\title{
PENGARUH MOTIVASI KERJA, DISIPLIN KERJA DAN LINGKUNGAN KERJA TERHADAP KINERJA MELALUI KEPUASAN KERJA PADA PEGAWAI PUSKESMAS KECAMATAN BALAPULANG KABUPATEN TEGAL
}

\author{
M. Abdul Aziz \\ Kantor Urusan Agama Balapulang
}

\begin{abstract}
The purpose of this study were 1) to describe the motivation, discipline, work environment, satisfaction and performance 2) to analyze the influence of motivation, discipline, work environment to the satisfaction 3) to analyze the influence of motivation, discipline, work environment on employee performance 4) for analyze the influence of satisfaction on the performance of employee 5) to analyze the influence of motivation, discipline, work environment to performance through employee satisfaction. Respondents in this study as many as 99 people. The respondents are the employees of clinic balapulang. This study uses Structural Equation Modeling (SEM) was run through AMOS 4.00 as a tool of analysis. The results of data analysis proves motivation, discipline, work environment, significantly influence satisfaction as evidenced from the value of standardized regression coefficients (beta) of 0.01, discipline on job satisfaction to get a value of 0.81 and work environment to job satisfaction of obtained a value of 0.29. motivation, discipline and work environment significantly influence the performance of employees as evidenced from the value of standardized regression coefficients (beta) leadership on teacher performance gain value of 0.20, discipline on employees performance gain value of 1,32 and work environment on employees performance gain value of 0.62. Satisfaction significantly influence the performance of employees. This is evidenced from the p-value is very small $(<0.001)$. Motivation, discipline, and work environment significantly influence performance through employees satisfaction as evidenced from the results sanggat pvalue small $(<0.001)$.
\end{abstract}

Keywords: motivation, disipmline, work environment, satisfaction, performance.

\section{PENDAHULUAN}

\section{A. Latar Belakang Masalah}

Keberhasilan suatu organisasi dalam mencapai tujuan, tidak dapat lepas dari faktor sumber daya manusianya. Sumber daya manusia merupakan hal yang sangat strategis dalam organisasi, artinya manusia memegang peranan penting dalam melakukan aktivitas untuk mencapai tujuan. Untuk itulah eksistensi sumber daya manusia dalam organisasi sangat kuat.

Manusia selalu berperan aktif dalam setiap kegiatan organisasi karena manusia menjadi perencana, pelaku, dan penentu terwujudnya tujuan organisasi. Tujuan tidak mungkin terwujud tanpa peran aktif pegawai meskipun alat-alat yang dimiliki suatu organisasi begitu modern. Dengan demikian keberhasilan suatu organisasi tidak hanya tergantung dari fasilitas yang ada melainkan juga 
tergantung pada faktor sumber daya manusia yang dimiliki.

Sehingga suatu organisasi membutuhkan sumber daya manusia yang potensial, baik pemimpin maupun pegawai dapat memberikan kontribusi yang baik dan melaksanakan tugas dengan optimal untuk mencapai tujuan . Karena semua kegiatan puskesmas akan melibatkan tindakan sumber daya manusia yang ada di dalamnya. Keberhasilan suatu organisasi dipengaruhi oleh kinerja pegawainya, suatu organisasi akan berupaya untuk meningkatkan kinerja pegawainya dengan harapan tujuan organisasi dapat tercapai.

Kinerja pada dasarnya adalah apa yang dilakukan atau tidak dilakukan pegawai. Kinerja pegawai adalah yang memengaruhi seberapa banyak mereka memberi kontribusi kepada organisasi antara lain termasuk kuantitas output, kualitas output, jangka waktu output, kehadiran di tempat kerja dan sikap kooperatif (Mathis dan Jackson, 2002).

Kinerja adalah hasil atau tingkat keberhasilan seseorang secara keseluruhan selama periode tertentu dalam melaksanakan tugas dibandingkan dengan berbagai kemungkinan standar hasil kerja, target atau sasaran atau kriteria yang ditentukan terlebih dahulu dan telah disepakati bersama (Rivai, 2005). Oleh karena itu, kinerja pegawai akan berjalan dengan efektif apabila didukung dengan motivasi kerja, disiplin kerja dan lingkungan kerja yang baik.

Motivasi kerja merupakan keinginan seseorang yang menyebabkan orang tersebut bertindak. Orang bertindak karena satu alasan yaitu untuk mencapai tujuan. Jadi, motivasi kerja adalah sebuah dorongan yang diatur oleh tujuan dan jarang muncul dalam kekosongan. Sedangkan menurut (Supardi dan Anwar, 2004) mengatakan motivasi kerja adalah keadaan dalam pribadi seseorang yang mendorong keinginan individu untuk melakukan kegiatan-kegiatan tertentu guna mencapai tujuan.

Disiplin kerja merupakan bentuk pengendalian diri pegawai dan pelaksanaan yang teratur dan menunjukkan tingkat kesungguhan tim kerja didalam sebuah organisasi. Nitisemito (2001) mengemukakan disiplin kerja sebagai suatu sikap, perilaku dan perbuatan yang sesuai dengan peraturan dari organisasi, baik tertulis maupun tidak tertulis.

Disiplin kerja merupakan tindakan manajemen untuk mendorong para anggota organisasi memenuhi tuntutan berbagai ketentuan yang harus ditaati oleh pegawai. Pendisiplinan pegawai adalah suatu bentuk pelatihan yang berusaha memperbaiki dan membentuk pengetahuan, sikap dan perilaku pegawai sehingga para pegawai dapat bekerja secara kooperatif dengan pegawai yang lain serta meningkatkan prestasi kerjanya (Sondang P.Siagian, 2002).

Di samping itu lingkungan kerja dalam suatu organisasi mempunyai peranan penting untuk kelancaran proses kegiatan, lingkungan kerja merupakan segala sesuatu yang ada di lingkungan pekerjaan yang dapat mempengaruhi dirinya dalam menjalankan tugas yang dibebankan. Sehingga tidak hanya faktor kepuasan pegawai dalam melaksanakan tugas tapi juga pengaruh seorang pegawai dalam peningkatan kinerjanya.

Berdasarkan uraian diatas maka perlu dilakukan penelitian dengan judul: "Pengaruh Motivasi Kerja, Disiplin Kerja dan Lingkungan Kerja terhadap Kinerja Pegawai Melalui Kepuasan Kerja Pada Pegawai Puskesmas Kecamatan Balapulang Kabupaten Tegal". 


\section{B. Perumusan Masalah}

Berdasarkan permasalahan tersebut maka dirumuskan suatu pertanyaan penelitian sebagai berikut:

1. Bagaimana deskripsi motivasi kerja, disiplin kerja, lingkungan kerja, kepuasan kerja dan kinerja pada pegawai Puskesmas Kecamatan Balapulang Kabupaten Tegal ?

2. Seberapa besar pengaruh motivasi kerja, disiplin kerja, lingkungan kerja terhadap kepuasan kerja pada pegawai Puskesmas Kecamatan Balapulang Kabupaten Tegal?

3. Seberapa besar pengaruh motivasi kerja, disiplin kerja, lingkungan kerja terhadap kinerja pada pegawai Puskesmas Kecamatan Balapulang Kabupaten Tegal?

4. Seberapa besar pengaruh kepuasan kerja terhadap kinerja pada pegawai Puskesmas Kecamatan Balapulang Kabupaten Tegal?

5. Seberapa besar pengaruh motivasi kerja, disiplin kerja, lingkungan kerja terhadap kinerja melalui kepuasan kerja pada pegawai Puskesmas Kecamatan Balapulang Kabupaten Tegal?

\section{Tujuan Penelitian}

1. Untuk mendeskripsikan motivasi kerja, disiplin kerja, lingkungan kerja, kepuasan kerja dan kinerja pada pegawai Puskesmas Kecamatan Balapulang Kabupaten Tegal.

2. Untuk mengetahui seberapa besar pengaruh motivasi kerja, disiplin kerja, lingkungan kerja terhadap kepuasan kerja pada pegawai Puskesmas Kecamatan Balapulang Kabupaten Tegal.

3. Untuk mengetahui seberapa besar pengaruh motivasi kerja, disiplin kerja, lingkungan kerja terhadap kinerja pada pegawai Puskesmas
Kecamatan Balapulang Kabupaten Tegal.

4. Untuk mengetahui seberapa besar pengaruh kepuasan kerja terhadap kinerja pada pegawai Puskesmas Kecamatan Balapulang Kabupaten Tegal.

5. Untuk mengetahui seberapa besar pengaruh motivasi kerja, disiplin kerja, lingkungan kerja terhadap kinerja melalui kepuasan kerja pada pegawai Puskesmas Kecamatan Balapulang Kabupaten Tegal.

\section{Manfaat Penelitian}

\section{Manfaat Teoritis}

a. Mendapatkan pengetahuan tentang pengaruh motivasi kerja, disiplin kerja, lingkungan kerja dan kepuasan kerja terhadap kinerja.

b. Sebagai dasar untuk penelitian selanjutnya, sehingga apa yang menjadi kekurangan penelitian dapat disempurnakan dan dikembangkan pada penelitian selanjutnya.

\section{Manfaat Praktis}

a. Manfaat bagi pegawai, hasil penelitian ini diharapkan dapat dijadikan bahan masukan bagi pegawai Puskesmas Kecamatan Balapulang untuk meningkatkan kinerjanya.

b. Manfaat bagi pimpinan, hasil penelitian ini diharapkan dapat dijadikan bahan pertimbangan bagi pimpinan untuk meningkatkan pembinaan kepada pegawai atau anggotanya.

c. Manfaat bagi lembaga, hasil penelitian ini diharapkan dapat memberikan sumbangan bagi dunia ilmu pengetahuan dan teknologi serta untuk memperkaya khasanah (kebaikan) khususnya dalam bidang pengembangan sumber daya manusia. 


\section{KAJIAN PUSTAKA}

\section{A. Landasan Teori}

\section{Konsep Kinerja}

Kinerja adalah hasil kerja secara kualitas dan kuantitas yang dicapai oleh seorang pegawai dalam melaksanakan tugasnya sesuai dengan tanggung jawab yang diberikan kepadanya (Mangkunegara, 2004). Kinerja pada dasarnya memiliki banyak arti berdasarkan sudut pandang atau pendapat para ahli. Kinerja yang disampaikan Herdiyanto (2003) yang mengadopsi arti kinerja dari Gibson (2001).

As'ad (2005) menjelaskan bahwa kepuasan kerja berhubungan erat dengan sikap dari karyawan terhadap pekerjaannya sendiri, situasi kerja, kerjasama dengan pimpinan dan kerjasama antar karyawan. Dengan demikian kepuasan kerja dapat ditunjukkan melalui sikap seseorang terhadap pekerjaan yang ditekuninya. Kepuasan kerja (job satisfaction) adalah keadaan emosional yang menyenangkan atau tidak menyenangkan dengan bagaimana para karyawan memandang pekerjaan mereka (Handoko 2006).

Motivasi kerja adalah hal yang menyebabkan, menyalurkan, dan mendukung perilaku manusia, supaya mau bekerja giat dan antusias mencapai hasil yang optimal (Hasibuan, 2003). Motivasi kerja semakin penting karena manajer membagikan pekerjaan pada bawahannya untuk dikerjakan dengan baik dan terintegrasi kepada tujuan yang ditentukan.

Setiap kegiatan yang dilakukan oleh seseorang didorong oleh suatu kekuatan dari dalam diri seseorang, kekuatan pendorong inilah yang disebut motivasi kerja (Fuad Mas'ud, 2002). Menurut Robbins (2012) motivasi kerja sebagai proses yang menjelaskan inten- sitas, arah, dan ketekunan seorang individu untuk mencapai tujuannya.

Menurut Hasibuan (2007:193) disiplin adalah kesadaran dan kesediaan seseorang menaati semua peraturan perusahaan dan norma-norma sosial yang berlaku. Kedisiplinan harus ditegakkan dalam suatu organisasi perusahaan. Tanpa dukungan disiplin karyawan yang baik, sulit bagi perusahaan untuk mewujudkan tujuannya. Jadi, kedisiplinan adalah kunci keberhasilan suatu perusahaan dalam mencapai tujuannya.

Menurut Sedarmayati (2009) definisi lingkungan kerja adalah keseluruhan alat perkakas dan bahan yang dihadapi, lingkungan sekitarnya di mana seseorang bekerja, metode kerjanya, serta pengaturan kerjanya baik sebagai perseorangan maupun sebagai kelompok.

Lingkungan kerja dalam suatu organisasi mempunyai peranan penting untuk kelancaran proses produksi karena lingkungan kerja yang baik tidak hanya dapat memuaskan pegawai dalam melaksanakan tugas, tetapi juga berpengaruh dalam meningkatkan kinerja pegawai.

Berdasarkan uraian di atas mengenai persoalan yang dihadapi dapat di gambarkan kerangka konseptual sebagai berikut :

Model Kerangka Konseptual

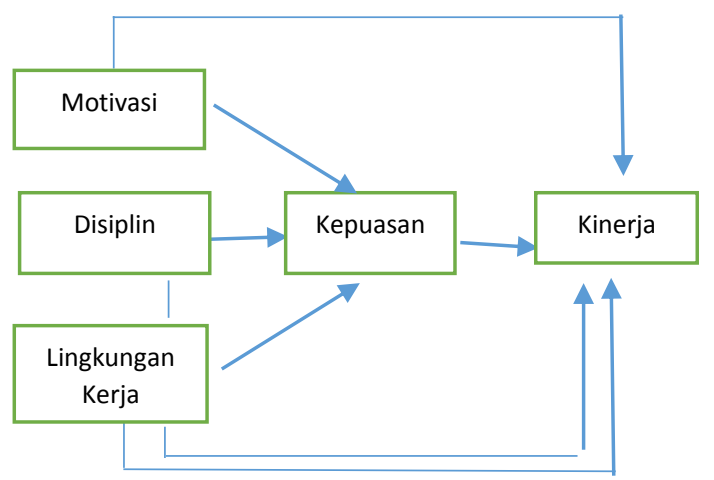




\section{E. Hipotesis}

1. Terdapat pengaruh motivasi kerja, disiplin kerja dan lingkungan kerja terhadap kepuasan kerjapada pegawai Puskesmas Kecamatan Balapulang Kabupaten Tegal.

2. Terdapat pengaruh motivasi kerja, disiplin kerja dan lingkungan kerja terhadap kinerja pada pegawai Puskesmas Kecamatan Balapulang Kabupaten Tegal

3. Terdapat pengaruh kepuasan kerja terhadap kinerja pada pegawai Puskesmas Kecamatan Balapulang Kabupaten Tegal.

4. Terdapat pengaruh motivasi kerja, disiplin kerja dan lingkungan kerja terhadap kinerja melalui kepuasan kerja pada pegawai Puskesmas Kecamatan Balapulang Kabupaten Tegal.

\section{METODE PENELITIAN}

\section{Populasi dan Sampel Penelitian}

\section{a. Populasi}

Sugiyono (2010:61) memberikan pengertian bahwa Populasi adalah wilayah generalisasi yang terdiri dari obyek atau subyek yang menjadi kuantitas dan karakteristik tertentu yang ditetapkan oleh peneliti untuk dipelajari dan kemudian ditarik simpulannya. Adapun populasi dalam penelitian ini adalah seluruh pegawai Puskesmas Kecamatan Balapulang sebanyak 99 orang pegawai.

\section{b. Sampel}

Menurut Suharsimi (2010:174), sampel adalah sebagian dari populasi yang diteliti. Bila populasi besar, dan peneliti tidak mungkin mempelajari semua yang ada pada populasi oleh karena alasan keterbatasan dana, tenaga, dan waktu, maka peneliti dapat menggunakan sampel yang diambil dari populasi tersebut.
Sampel yang diambil dari populasi harus benar-benar representatif. Dalam hal ini peneliti menggunakan seluruh populasi sebanyak 99 orang untuk dijadikan sampel dalam penelitian atau biasa disebut studi populasi.

\section{Teknik Analisis Data dan Pengujian Hipotesis}

Untuk menganalisis data digunakan The Structural Equation Modeling (SEM) dari paket softwarestatistik AMOS 4.0 dalam model dan pengkajian hipotesis. Model persamaan structural, Structural Equation Model (SEM) adalah sekumpulan teknik-teknik statistical yang memungkinkan pengujian sebuah rangkaian hubungan relatif "rumit" secara simultan (Ferdinand, 2011).

Alasan penelitian ini dilakukan dengan SEM dikarenakan dalam model penelitian ini digunakan variable intervening disamping itu masingmasing variable diukur melalui indikator-indikator sehingga perlu dilakukan uji kelayakan model apakah model yang dianalisis dalam penelitian ini sesuai dengan keadaan yang sebenarnya.

\section{HASIL PENELITIAN DAN PENGUJIAN HIPOTESIS}

\section{Uji Validitas Instrumen}

Validitas adalah suatu ukuran yang menunjukan tingkat kevalidan/ kesahihan suatu intrumen.pernyataan untuk variabel motivasi, disiplin , lingkungan kerja, kepuasan, dan kinerja pegawai sudah valid karena memiliki nilai korelasi di atas $r_{\text {tabel }}$ sebesar 0,195.

\section{Uji Reliabilitas Instrumen}

Di samping pengujian validitas, terhadap instrumen yang akan digunakan juga dilakukan pengujian reliabilitas. Menurut Suharsimi instrumen harus reliabel mengandung arti bahwa 
instrumen tersebut cukup baik sehingga mampu mengungkap data yang bisa dipercaya.

Hasil Uji Reliabilitas Instrumen Variabel

\begin{tabular}{|c|l|c|c|c|}
\hline No. & Variabel & Reliabilitas & $\begin{array}{c}\text { Standar } \\
\text { Koefisien } \\
\text { Alfa }\end{array}$ & Keterangan \\
\hline 1. & $\begin{array}{l}\text { Motivasi } \\
\text { Kerja }\end{array}$ & 0,786 & 0,6 & Reliabel \\
\hline 2. & $\begin{array}{l}\text { Disiplin } \\
\text { Kerja }\end{array}$ & 0,773 & 0,6 & Reliabel \\
\hline 3. & $\begin{array}{l}\text { Lingkungan } \\
\text { Kerja }\end{array}$ & 0,896 & 0,6 & Reliabel \\
\hline 4. & $\begin{array}{l}\text { Kepuasan } \\
\text { Kerja }\end{array}$ & 0,871 & 0,6 & Reliabel \\
\hline 4. & Kinerja & 0,865 & 0,6 & Reliabel \\
\hline
\end{tabular}

\section{A. Responden Menurut Jenis Kelamin}

Berdasarkan hasil penelitian yang telah dilaksanakan diperoleh data seperti yang terlihat dalam Tabel 10 dapat dinyatakan bahwa responden yang terdiri dari 99 orang responden terdiri dari 27 orang responden $(27,27 \%)$ mempunyai jenis kelamin laki-laki dan 72 orang $(72,73 \%)$ responden perempuan.

Tabel 10

Responden Menurut Jenis Kelamin

\begin{tabular}{|l|c|c|}
\hline $\begin{array}{c}\text { Jenis } \\
\text { Kelamin }\end{array}$ & $\begin{array}{c}\text { Frekuensi } \\
\text { (Orang) }\end{array}$ & $\begin{array}{c}\text { Persentase } \\
\mathbf{( \% )}\end{array}$ \\
\hline Laki-Laki & 27 & $27.27 \%$ \\
\hline Perempuan & 72 & $72.73 \%$ \\
\hline Jumlah & $\mathbf{9 9}$ & $\mathbf{1 0 0 \%}$ \\
\hline
\end{tabular}

Sumber : Data primer, diolah 2016

\section{B. Responden Menurut Umur}

Berdasarkan hasil penelitian yang telah dilaksanakan diperoleh data seperti yang terlihat dalam Tabel berikut dapat dinyatakan bahwa responden yang terdiri dari 99 orang responden terdiri dapat diklasifikasikan dalam 2 golongan usia. Sebanyak 16 orang responden $(16,16 \%)$ mempunyai usia antara 21- 40 tahun, dan yang berusia lebih dari 41 tahun sebanyak 83 responden $(83,84 \%)$.
Tabel 11

Responden Menurut Umur

\begin{tabular}{|l|c|c|}
\hline $\begin{array}{c}\text { Umur } \\
\text { (Tahun) }\end{array}$ & $\begin{array}{c}\text { Frekuensi } \\
\text { (Orang) }\end{array}$ & $\begin{array}{c}\text { Persentase } \\
\mathbf{( \% )}\end{array}$ \\
\hline $\begin{array}{l}21 \mathrm{Thn}-40 \\
\text { Thn }\end{array}$ & 83 & $83,84 \%$ \\
\hline$>=41 \mathrm{Thn}$ & 16 & $16,16 \%$ \\
\hline Jumlah & $\mathbf{9 9}$ & $\mathbf{1 0 0 \%}$ \\
\hline
\end{tabular}

Sumber : Data primer, diolah 2016

\section{Analisis Asumsi Structural Equating Modeling (SEM)}

Untuk melakukan analisis inferensial dalam penelitian ini digunakan teknik Structural Equation Modeling (SEM). Dalam melakukan analisis dengan teknik Structural Equation Modeling (SEM).

\section{Pengujian Hipotesis}

Hasil analisis SEM dari penelitian ini dijabarkan dalam langkah pengujian hipotesis sebagai berikut:

\section{a. Pengujian Hipotesis 1}

$\mathrm{H}_{1}$ : Terdapat pengaruh antara motivasi, disiplin dan lingkungan terhadap kepuasan pegawai Puskesmas Kecamatan Balapulang.

Adapun hasil analisis SEM yang dilakukan diuraikan dalam gambar di bawah ini : Hasil Analisis Pengaruh Variabel Motivasi, Disiplin dan Lingkungan terhadap Variabel Kepuasan Kerja

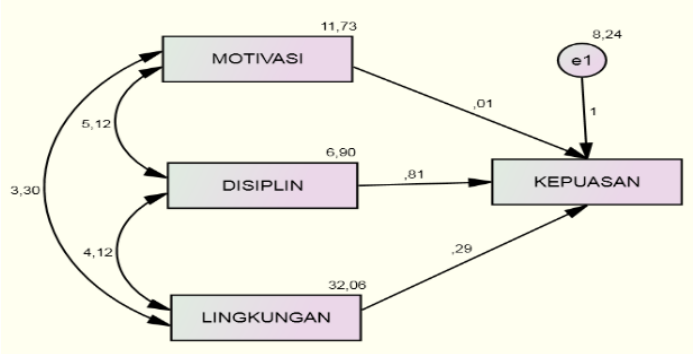


Pada gambar di atas dapat dijelaskan bahwa nilai koefisien regresi terstandar (beta) motivasi $\left(\mathrm{X}_{1}\right)$ terhadap kepuasan pegawai memperoleh nilai sebesar 0,01 , disiplin $\left(X_{2}\right)$ terhadap kepuasan pegawai memperoleh nilai sebesar 0,81, sedangkan lingkungan (X3) terhadap kepuasan pegawai memperoleh nilai sebesar 0,29. Dari nilai ketiga koefisien ini dapat disimpulkan bahwa variable disiplin lebih penting dalam mempengaruhi kepuasan kerja pegawai dibandingkan dengan variabel motivasi dan lingkungan.

\section{b. Pengujian Hipotesis 2}

$\mathrm{H}_{1}$ : Terdapat pengaruh antara motivasi, disiplin dan lingkungan terhadap kinerja pegawai Puskesmas Kecamatan Balapulang.

Adapun hasil analisis SEM yang dilakukan diuraikan dalam gambar di bawah ini :

Hasil Analisis Pengaruh Variabel Motivasi, Disiplin dan Lingkungan Terhadap Variabel Kinerja

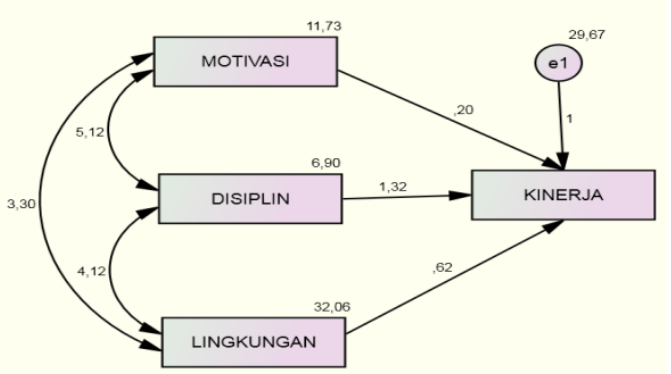

Pada gambar di atas dapat dijelaskan bahwa nilai koefisien regresi terstandar (beta) motivasi $\left(\mathrm{X}_{1}\right)$ terhadap kinerja pegawai memperoleh nilai sebesar 0,20, disiplin $\left(\mathrm{X}_{2}\right)$ terhadap kinerja memperoleh nilai sebesar 1,32, sedangkan lingkungan (X3) terhadap kinerja memperoleh nilai sebesar 0,62. Dari nilai ketiga koefisien ini dapat disimpulkan bahwa variable disiplin lebih penting dalam mempengaruhi kinerja pegawai dibandingkan dengan variabel motivasi dan lingkungan.

\section{c. Pengujian Hipotesis 3}

$\mathrm{H}_{3}$ : Terdapat pengaruh antara kepuasan terhadap kinerja pegawai Puskesmas Kecamatan Balapulang.

Adapun hasil analisis SEM yang dilakukan diuraikan dalam gambar di bawah ini :

Hasil Analisis Pengaruh Variabel Kepuasan

Kerja terhadap Variabel Kinerja Pegawai

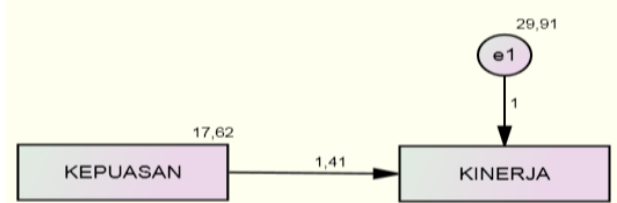

Pada gambar di atas dapat dijelaskan bahwa nilai koefisien regresi terstandar (beta) kepuasan kerja $\left(\mathrm{Y}_{1}\right)$ terhadap kinerja pegawai $\left(\mathrm{Y}_{2}\right)$ memperoleh nilai sebesar 1,41

\section{d. Pengujian Hipotesis 4}

$\mathrm{H}_{4}$ : Terdapat pengaruh antara motivasi, disiplin dan lingkungan kerja terhadap kinerja pegawai melalui kepuasan pegawai Puskesmas Kecamatan Balapulang.

Adapun hasil analisis SEM yang dilakukan diuraikan dalam gambar di bawah ini :

\section{Gambar 11}

Hasil Analisis Pengaruh Variabel Motivasi, Disiplin dan Lingkungan terhadap Variabel Kinerja Pegawai melalui Kepuasan Kerja

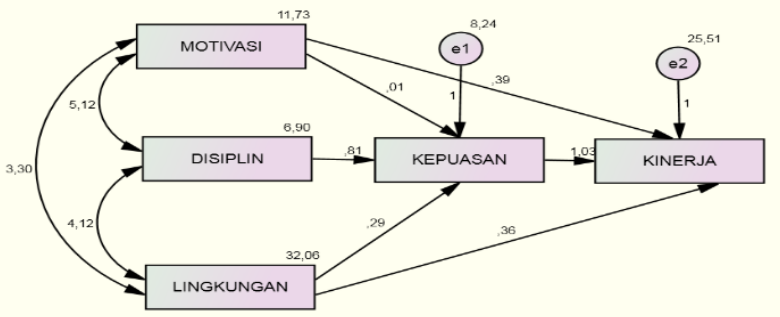


Pada gambar di atas dapat dijelaskan bahwa nilai koefisien regresi terstandar (beta) Motivasi $\left(\mathrm{X}_{1}\right)$, Disiplin $\left(\mathrm{X}_{2}\right)$ dan Lingkungan kerja (X3) terhadap Kinerja Pegawai $\left(\mathrm{Y}_{2}\right)$ melalui Kepuasan Kerja Pegawai (Y1) memperoleh nilai sebesar 1,03 .

\section{SIMPULAN DAN SARAN}

\section{A. Simpulan}

Setelah dilakukan hasil analisis dan pengujian terhadap hipotesis yang diujikan, maka diambil kesimpulan atas hipotesis-hipotesis tersebut. Berikut ini kesimpulan penelitian atas empat hipotesis penelitian yang digunakan.

Motivasi, disiplin dan lingkungan berpengaruh secara signifikan terhadap kinerja melalui kepuasan pegawai Puskesmas Kecamatan Balapulang. Hal tersebut dibuktikan dari hasil p-value berupa tiga buah tanda asterisk $(* * *)$, yang berarti nilai $\mathrm{p}$-value sanggat kecil $(<0,001)$, maka dengan demikian bahwa hipotesis yang menyatakan terdapat pengaruh antara Motivasi, Disiplin dan Lingkungan terhadap Kinerja Pegawai melalui Kepuasan Pegawai Puskesmas Kecamatan Balapulang terbukti kebenarannya.

\section{B. Saran}

Adapun saran yang diberikan untuk menelitian yang akan datang ada sebagai berikut:

1. Penelitian selanjutnya diharapkan menggunakan jenis instansi lain sebagai obyek penelitian.

2. Peneliti selanjutnya diharapkan untuk mengembangkan penelitian ini dengan juga meneliti faktor-faktor lain yang berpengaruh terhadap kinerja pegawai yang tidak diteliti oleh peneliti.

\section{DAFTAR PUSTAKA}

Arikunto, Suharsimi, 2002, Prosedur Penelitian Suatu Pendekatan Praktik, Edisi Revisi, Cetakan Kedelapan. Penerbit Rineka Cipta. Jakarta.

As`ad Moh. 2003. Psikologi Industri. Galia Indonesia. Yogyakarta.

Dessler, Gary, 2009. Manajemen Sumber Daya Manusia. Jakarta.

Dharma, Surya. 2002. Paradigma Baru: Manajemen Sumber Daya Manusia. Amara Books. Yogyakarta.

Fadel, Muhammad. 2007. Reinventing Government (Pengalaman Dari Daerah). PT. Elex Media Komputindo. Jakarta

Fanny Putriningrum. 2015. Pengaruh Kompensasi, Motivasi, Disiplin Kerja, Dan Lingkungan Kerja Terhadap Kinerja Pegawai PT. Sampharindo Perdana Semarang. Dokumen Karya Ilmiah Universitas Dian Nuswantoro Semarang. eprints.dinus.ac.id/8767/1/jurnal_13446.pdf

Fathonah, Sitidan Ida Utami. 2012. Pengaruh Kompensasi, Pengembangan Karir, Lingkungan Kerjadan Komitmen Organsias terhadap Kepuasan Kerja Pegawai Sekretariat Daerah Kabupaten Karanganyar dengan Keyakinan Diri (self Efficacy) Sebagai Variabel Pemoderasi. Jurnal STIEAUB Surakarta. Fakhar (2014) 
FuadMas'ud, 2004. Survai Diagnosis Organisasional (Konsepdan Aplikasi), Badan Penerbit Universitas Diponegoro.

Gita Sugiarti. 2013. Pengaruh Lingkungan Kerja, Budaya Organisasi Dan Kompensasi Terhadap Kepuasan Kerja Untuk Meningkatkan Kinerja Pegawai (Studi Pada Fakultas Ekonomi Universitas 17 Agustus 1945 Semarang. Jurnal serata citya Jurnal Ilmiah UNTAG Semarang. Vol 1, No 2.

Hasibuan, Malayu S.P. 2011. Manajemen Sumber Daya Manusia. Jakarta: PT. Bumi Aksara.

Hasibuan, Malayu, S.P., 2012. Manajemen Sumber Daya Manusia. Edisi Revisi: PT. Bumi Aksara, Jakarta

Hasibuan, Malayu S. P. 2001.Manajemen Sumber Daya Manusia, Edisi Revisi: Bumi Aksara. Jakarta.

Hasibuan, Malayu, S.P. 2003. Manajemen Dasar, Pengertiandan Masalah. PT. Toko Gunung Agung. Jakarta.

Ismiyarto, Sri Suwitri, Y. Warella \& Sundarso. 2015. Organizational Culture, Motivation, Job Satisfaction and Performance of Employees toward the Implementation of Internal Bureaucracy Reform in the Ministry for the Empowerment of State Apparatus and Bureaucracy Reform (The Ministry of $P A N R B)$. Journal of Management and Sustainability; Vol. 5, No. 1; 2015.

I Putu Sedhana Yasa. 2013. Pengaruh Kompensasi Dan Lingkungan Kerja Terhadap Kepuasan Kerja Dan Kinerja Pegawai Pada Karma Jimbaran. Jurnal Vol 3, No 10 (2014). ojs.unud.ac.id

Irawan, Prasetya. 2006. Penelitian Kualitatif \& Kuantitatif Untuk Ilmu-Ilmu Sosial. Departemen Ilmu Adminstrasi FISIP UI.

Jonathan Sarwono, 2007.Analisis Jalur untuk Riset Bisnis dengan SPSS. Andi Offset. Yogyakarta.

Kirkpatrick, D.L., Kirkpatrick, J.D., 2006. Evaluating Training Program; The FourLevels, 3rd Edition. Berrett Koehler, Inc. San Fransisco

Kreitner, Robert, dan Angelo Kinicki. 2001. Organizational Behavior. New York: McGraw-Hill Companies, Inc.

Mangkunegara, DR. A.A. Anwar Prabu. 2005. Evaluasi Kinerja SDM. Penerbit Refika Aditama. Bandung

Mangkunegara, DR. A.A. Anwar Prabu. 2005. Evaluasi Kinerja SDM. Penerbit Refika Aditama. Bandung.

Mathis, R dan Jackson, W.2006. Human Resources Development (Track MBA series/ terjemahan). Prestasi Pustaka. Jakarta.

Nurcahyani, Ni Made \& I.G.A. Dewi Adnyani. 2016. Pengaruh Kompensasi Dan Motivasi Terhadap Kinerja Pegawai Dengan Kepuasan Kerja Sebagai Variabel Intervening. E-Jurnal Manajemen Unud, Vol. 5, No.1, 2016: 500 - 532 ISSN: 2302-8912 500 Bali, Indonesia Nursalam, 2008

Pasolong, Harbani. 2010. Teori Administrasi Publik. Alfabeta. Bandung. 
Raddana. 2013. Faktor-faktor Yang Mempengaruhi Kinerja Nusa Tenggara Barat. Jurnal Administrasi Publik Vol. 11 No. 2.

Rivai, Veithzal. 2004. Performa Apraisal. Jakarta : Rajawali Press

Rivai, Veitzal, 2003, Manajemen Sumber Daya Manusia untuk Perusahaan: Dari. Teori ke Praktik. PT. Raja Grafindo Persada. Jakarta.

Rivai, Veitzal. 2004. Manajemen Sumber Daya Manusia Untuk Perusahaan : Dari Teori Ke Praktik. PT. Raja Grafindo Persada. Jakarta.

Rivai, Veitzal\& Ahmad Fawzi Mohd Basri. 2005. Performance Appraisal Sistem Yang Tepat Untuk Menilai Kinerja Karyawan Dan Meningkatkan Daya Saing Perusahaan. PT. Raja Grafindo Persada,.Jakarta.

Sedarmayanti. 2001. Sumber Daya Manusia dan Produktivitas Kerja. Mandar Maju. Bandung. 